\title{
Inhibition of airway epithelial-to-mesenchymal transition and fibrosis by kaempferol in endotoxin-induced epithelial cells and ovalbumin-sensitized mice
}

\author{
Ju-Hyun Gong, In-Hee Cho, Daekeun Shin, Seon-Young Han, Sin-Hye Park and Young-Hee Kang
}

Chronic airway remodeling is characterized by structural changes within the airway wall, including smooth muscle hypertrophy, submucosal fibrosis and epithelial shedding. Epithelial-to-mesenchymal transition (EMT) is a fundamental mechanism of organ fibrosis, which can be induced by TGF- $\beta$. In the in vitro study, we investigated whether 1-20 $\mu \mathrm{M}$ kaempferol inhibited lipopolysaccharide (LPS)-induced bronchial EMT in BEAS-2B cells. The in vivo study explored demoting effects of $10-20 \mathrm{mg} / \mathrm{kg}$ kaempferol on airway fibrosis in BALB/c mice sensitized with ovalbumin (OVA). LPS induced airway epithelial TGF- $\beta 1$ signaling that promoted EMT with concurrent loss of E-cadherin and induction of $\alpha$-smooth muscle actin ( $\alpha$-SMA). Nontoxic kaempferol significantly inhibited TGF- $\beta$-induced EMT process through reversing $\mathrm{E}$-cadherin expression and retarding the induction of $\mathrm{N}$-cadherin and $\alpha$-SMA. Consistently, OVA inhalation resulted in a striking loss of epithelial morphology by displaying myofibroblast appearance, which led to bronchial fibrosis with submucosal accumulation of collagen fibers. Oral administration of kaempferol suppressed collagen deposition, epithelial excrescency and goblet hyperplasia observed in the lung of OVA-challenged mice. The specific inhibition of TGF- $\beta$ entailed epithelial protease-activated receptor-1 (PAR-1) as with $20 \mu \mathrm{M}$ kaempferol. The epithelial PAR-1 inhibition by SCH-79797 restored E-cadherin induction and deterred $\alpha$-SMA induction, indicating that epithelial PAR-1 localization was responsible for resulting in airway EMT. These results demonstrate that dietary kaempferol alleviated fibrotic airway remodeling via bronchial EMT by modulating PAR1 activation. Therefore, kaempferol may be a potential therapeutic agent targeting asthmatic airway constriction.

Laboratory Investigation (2014) 94, 297-308; doi:10.1038/labinvest.2013.137; published online 30 December 2013

KEYWORDS: airway fibrosis; epithelial-to-mesenchymal transition; kaempferol; protease-activated receptor-1; transforming growth factor- $\beta$

Asthma is characteristic of the structural remodeling of airway epithelium accompanying epithelial damage, smooth muscle thickening and increased deposition of extracellular matrix (ECM) components, such as collagens. ${ }^{1-3}$ Airway fibrosis entails epithelial cell modulation, matrix expansion and increased submucosal cells expressing profibrotic cytokines and growth factors. ${ }^{4-6}$ Epithelial-to-mesenchymal transition (EMT) has an important role in the progression of airway epithelial fibrosis and downregulation of tight junction. ${ }^{7}$ EMT, a reversible process in which epithelial cells transdifferentiate into cells with mesenchymal characteristics, is widely considered to be a crucial process in fibrosis as well as inflammation and apoptosis. ${ }^{8}$ Growth factors, inflammatory mediators and matricellular proteins are known to induce downregulation of epithelial cell-cell adhesion and promote mesenchymal gene expression of vimentin and $\alpha$-smooth muscle actin ( $\alpha$-SMA). ${ }^{7}$ The profibrotic cytokine transforming growth factor (TGF)- $\beta$ is one of the main mediators involved in tissue remodeling in the asthmatic lung, particularly being related to the subepithelial fibrosis., ${ }^{9,10}$ TGF- $\beta$ is produced in the airways by inflammatory cells infiltrated in the bronchial mucosa, as well as by resident structural cells of the airway wall. ${ }^{9}$ The TGF- $\beta$-induced EMT of alveolar epithelial cells may contribute to the generation of myofibroblasts and airway remodeling in severe asthma and fibrotic lung diseases. ${ }^{11}$ Although high expression of TGF- $\beta$ is observed in patients with asthma, controversy remains whether the concentration of TGF- $\beta$ correlates with disease severity. ${ }^{10}$ 
Proteinase-activated receptors (PAR) are widely distributed throughout the airways, and their activation appears to modulate bronchomotor tone and produce respiratory inflammation in respiratory tract disorders. ${ }^{12}$ PAR are a novel family of $G$ protein-coupled receptors, through which signaling involves the cleavage of an extracellular region of the receptor by serine proteinases, such as trypsin and thrombin. ${ }^{13}$ PAR-1 has been shown to be an important player in the development of pulmonary fibrosis. Thus PAR-1 represents an exciting target for clinical intervention in fibrotic diseases. ${ }^{14}$ Activation of PAR-2 inhibits bronchoconstriction and airway hyperresponsiveness and modulates the immune response in experimental allergic asthma. ${ }^{15,16}$ However, there is a debate as to whether the major responses to PAR activation are an augmentation or attenuation of airways inflammation. PAR-2 activation has a protective role in airways of lipopolysaccharide (LPS)-treated rats, increasing relaxant response bronchorelaxant response and preserving bronchial functionality. ${ }^{17}$ Nevertheless, an understanding of PAR-induced cellular events and the consequences of receptor blockade may help in the development of novel therapeutic strategies targeted to prevent lung destruction.

Kaempferol is a natural flavonol-type flavonoid isolated from tea, broccoli, citrus fruits, apples and other plant sources. Kaempferol is a strong antioxidant preventing oxidative cell damage and inhibiting oxidation of LDL and induction of inflammatory mediators involved in the initial steps of atherosclerotic plaque formation. ${ }^{18,19}$ In our previous studies, ${ }^{20,21}$ kaempferol suppressed eosionphil infiltration and airway inflammation in airway epithelial cells and in mice with allergic asthma. There are numerous studies dealing with inhibitory effects of polyphenols on airway dysfunction and disorders. The flavonol quercetin can inhibit human neutrophil elastase-induced mucin 5AC expression in human airway epithelial cells. ${ }^{22}$ Resveratrol present in red wine reduces subepithelial collagen deposition and attenuates airway hyperreactivity. ${ }^{23}$ In addition, goblet cell metaplasias, thickness of airway smooth muscle, airway fibrosis and AHR to acetylcholine were markedly abrogated in limonene-treated mice. ${ }^{24}$ However, the inhibitory effects of kaempferol on airway fibrosis are not well defined.

Based on the literature evidence for kaempferol, this study investigated whether kaempferol attenuated pulmonary fibrosis by blocking TGF- $\beta 1$ induction of EMT in LPS-exposed epithelial cells and in ovalbumin (OVA)-challenged mice. Collagen secretion, E-cadherin loss and $\mathrm{N}$-cadherin/ $\alpha$-SMA induction were also elucidated for TGF- $\beta$-associated EMT. Furthermore, the role of PAR-1 was investigated as a target for the therapeutic intervention of kaempferol in airway fibrosis. Kaempferol alleviated fibrotic airway remodeling via bronchial EMT by modulating induction of TGF- $\beta$ and PAR-1.

\section{MATERIALS AND METHODS \\ Chemicals}

M199, human epidermal growth factor (EGF), hydrocortisone, gelatin, human insulin, apotransferrin, LPS and albumin from chicken egg white were obtained from the Sigma-Aldrich Chemical (St Louis, MO, USA), as were all other reagents, unless specifically stated elsewhere. Fetal bovine serum (FBS), penicillin-streptomycin and trypsinEDTA were purchased from the Lonza (Walkersville, MD, USA). Human bronchial airway epithelial cell line BEAS-2B was provided by the American Type Culture Collection (Manassas, VA, USA). Imject alum was purchased from Thermo Fisher Scientific (Rodkford, IL, USA). Antibodies of human TGF- $\beta 1$, TGF- $\beta$ RI, TGF- $\beta$ RII and E-cadherin were obtained from Cell Signaling Technology (Beverly, CA, USA). Antibodies of collagen IV, $\alpha$-SMA and human membrane type 1-matrix metalloproteinase (MT1-MMP), and PAR-1 inhibitor SCH-79797 were provided by Santa Cruz Biotechnology (Santa Cruz, CA, USA). Human recombinant protein of TGF- $\beta$ and human tissue inhibitor of MMP-2 (TIMP-2) antibody were provided by R\&D systems (Minneapolis, MN, USA). Antibodies of human N-cadherin and human proteinase-activated receptor 1 (PAR-1) were obtained from Abcam (Cambridge, UK). TGF- $\beta$ RI inhibitor (HTS 466284) was supplied by Merck Chemicals (Darmstadt, Germany). Human $\beta$-actin antibody was obtained from Sigma-Aldrich Chemicals. Horseradish peroxidase-conjugated goat anti-rabbit IgG, goat antimouse and donkey anti-goat IgG were obtained from Jackson ImmunoResearch Laboratories (West Grove, PA, USA). Albumin from bovine serum (essentially fatty acid free) and skim milk were acquired from Becton Dickinson Company (Sparks, MD, USA).

\section{BEAS-2B Cell Culture}

BEAS-2B cells were cultured in $25 \mathrm{mM}$ HEPES-buffered M199 containing $10 \%$ FBS, $2 \mathrm{mM}$ glutamine, $100 \mathrm{U} / \mathrm{ml}$ penicillin, $100 \mu \mathrm{g} / \mathrm{ml}$ streptomycin supplemented with $2.5 \mu \mathrm{g} / \mathrm{ml}$ insulin, $0.361 \mu \mathrm{g} / \mathrm{ml}$ hydrocortisone, $2.5 \mu \mathrm{g} / \mathrm{ml}$ apotransferrin and $20 \mathrm{ng} / \mathrm{ml}$ human EGF. The 90-95\% confluence of BEAS-2B cells was sustained at $37^{\circ} \mathrm{C}$ in an atmosphere of $5 \% \mathrm{CO}_{2}$ during cell culture experiments. To induce airway fibrosis by EMT, BEAS-2B cells were seeded at $80 \%$ confluence a day before starting the treatment of $1-20 \mu \mathrm{M}$ kaempferol on six-well or 12-well plates and then stimulated with LPS or TGF- $\beta 1$ for up to 3 days.

\section{Induction of Airway Fibrosis in a Murine Model}

Six-week-old male BALB/c mice (Hallym University Breeding Center for Laboratory Animals) were kept on a $12 \mathrm{~h}$ light/ $12 \mathrm{~h}$ dark cycle at $23 \pm 1{ }^{\circ} \mathrm{C}$ with $50 \pm 10 \%$ relative humidity under specific pathogen-free conditions. Mice were fed a non-purified diet (RodFeedTM, DBL, Umsung, Korea) and were provided with water ad libitum at the Animal Facility of 
Hallym University. The non-purified diet composition was as follows: NLT (Not Less Than) 20.5\% crude protein, NLT $3.5 \%$ crude fat, NMT (Not More Than) $8.0 \%$ crude fiber, NMT $8.0 \%$ crude ash, NLT $0.5 \%$ calcium, and NLT $0.5 \%$ phosphorus. Mice were allowed to acclimatize for 1 week before beginning experiments. Mice were divided into four subgroups ( $n=6$ for each subgroup). Mice were sensitized with $20 \mu \mathrm{g}$ OVA dissolved in a solution of $30 \mu \mathrm{l}$ PBS and $50 \mu \mathrm{l}$ Imject Alum by subcutaneous injection twice on days 0 and 14. Kaempferol solution $(0.1 \mathrm{ml}, 10$ or $20 \mathrm{mg} / \mathrm{kg}$ BW $)$ was orally administered to OVA-sensitized mice $1 \mathrm{~h}$ before OVA challenge. On days 28, 29 and 30, 5\% OVA inhalation to mice was conducted for $20 \mathrm{~min}$ in a plastic chamber linked to an ultrasonic nebulizer (Clenny $^{2}$ Aerosol, Medel, S. Polo di Torrile, Italy). Control mice were sensitized and challenged with PBS as the OVA vehicle. All mice were killced with an anesthetic $(2 \mu \mathrm{l} / \mathrm{kg}$ rompun and $8 \mu \mathrm{l} / \mathrm{kg}$ zoletil, intraperitoneal injection) $24 \mathrm{~h}$ after the last challenge (day 30 ). The right lungs were collected, frozen in liquid nitrogen and kept at $-80^{\circ} \mathrm{C}$ for the extraction, and the left lungs were preserved and fixed in $4 \%$ paraformaldehyde and then used for staining.

All experiments were approved by the Committee on Animal Experimentation of Hallym University and performed in compliance with the University's Guidelines for the Care and Use of Laboratory Animals. None of the mice died, and no apparent signs of exhaustion were observed during the experimental period.

\section{Western Blotting Analysis}

Western blotting analysis was conducted using whole-cell lysates and collected culture media prepared from BEAS-2B cells at a density of $3.0 \times 10^{5}$ cells. Whole BEAS-2B cell lysates were prepared in a lysis buffer containing $1 \mathrm{M} \beta$-glycerophosphate, $1 \% \beta$-mercaptoethanol, $0.5 \mathrm{M} \mathrm{NaF}, 0.1 \mathrm{M} \mathrm{Na}_{3} \mathrm{VO}_{4}$ and protease inhibitor cocktail. Cell lysates containing equal amounts of total proteins or equal volumes of culture media were electrophoresed on 6-12\% sodium dodecyl sulfate polyacrylamide gel electrophoresis (SDS-PAGE) and transferred onto a nitrocellulose membrane. Nonspecific binding was blocked by soaking the membrane in a TBS-T buffer (50 mM Tris- $\mathrm{HCl}$ (pH 7.5), $150 \mathrm{mM} \mathrm{NaCl}$ and $0.1 \%$ Tween 20 ) supplemented with $3 \%$ bovine serum albumin for $3 \mathrm{~h}$. The membrane was incubated with an antibody to human proteins of TGF- $\beta 1$, TGF- $\beta$ RI, TGF- $\beta$ RII, collagen IV, $\alpha$-SMA, PAR-1, E-cadherin, MT1-MMP and TIMP-2. Subsequently, the membrane was then incubated with a secondary antibody of goat anti-rabbit IgG or goat anti-mouse IgG conjugated to horseradish peroxidase. Each protein level was determined by using the Supersignal West Pico Chemiluminescence detection reagents (Pierce Biotechnology, Rockford, IL, USA) and Konica X-ray film (Konica, Tokyo, Japan). Incubation with mouse anti-human $\beta$-actin antibody was conducted for the comparative control.

\section{Lung Immunohistochemical Staining}

For the immunofluorescent histochemical analysis, paraffinembedded trachea tissue sections $(5 \mu \mathrm{m}$ thick) were used. The sections were placed on glass slides, de-paraffinated and hydrated with xylene and graded alcohol. The sections were pre-incubated in a boiling sodium citrate buffer $(10 \mathrm{mM}$ sodium citrate, $0.05 \%$ Tween $20, \mathrm{pH}$ 6.0) for antigen retrieval. Specific primary antibody against mouse E-cadherin, $\alpha$-SMA and MMP-2 was incubated with the tissue sections overnight. Subsequently, the tissue sections were incubated for $1 \mathrm{~h}$ with Cy3-conjugated anti-goat IgG. Nuclear staining was done with 4',6-diamidino-2-phenylindole (DAPI). Each slide was mounted in VectaMount mounting medium (Vector Laboratories, Burlingame, CA, USA). Images of each slide were taken using an optical microscope system (Axiomager, Zeiss, Germany). Protein levels of $\alpha$-SMA were quantified by the image analysis program of the microscope system.

\section{Masson Trichrome Staining}

For the histological analyses, lung specimens were obtained at the end of the experiments and fixed in $10 \%$ buffered formalin. The paraffin-embedded lung specimens were sectioned at $5 \mu \mathrm{m}$ thickness, de-paraffinized and stained with Masson trichrome for the light microscopic visualization of collagen fibers and muscle fibers. The stained tissue sections were examined using an Optical microscope AXIOIMAGER (Zeiss, Gottingen, Germany), and five images were taken for each section.

\section{Immunocytochemistry}

Immunocytochemical staining for monolayer cells of BEAS-2B cells grown on glass coverslips was conducted using human $\mathrm{N}$-cadherin antibody and 3,3'-diaminobenzidine (DAB) as chromogen. BEAS-2B cells were fixed with $4 \%$ formaldehyde for $15 \mathrm{~min}$ and permeated with $0.1 \%$ Triton X-100 for $2 \mathrm{~min}$ on ice. Cells were blocked using a $4 \%$ FBS for $1 \mathrm{~h}$, and anti-human N-cadherin was applied to cells. After overnight incubation, triple washing was conducted and incubation with peroxidase-conjugated goat anti-rabbit IgG was achieved for $1 \mathrm{~h}$. For the N-cadherin visualization, the cells were developed with $\mathrm{DAB}$ to produce brownish staining.

Immunofluorescent cytochemical analysis was performed using human PAR-1 antibody and Cy3-conjugated anti-rabbit IgG. Nuclear staining was performed with DAPI. Each slide was mounted in VectaMount mounting medium (Vector Laboratories, Burlingame, CA, USA). Images of each slide were taken using an optical microscope system (Axiomager, Zeiss, Oberkochen, Germany). The PAR-1 protein levels were quantified with an image analysis program from the microscope system.

\section{Gelatin Zymography}

For the measurement of MMP-2 activity of culture media, gelatin zymography was conducted. Briefly, culture media 
were subjected to electrophoresis on $8 \%$ SDS-PAGE $(0.3 \mathrm{M}$ Tris- $\mathrm{HCl}$ (pH 6.8), 4\% SDS, $20 \%$ glycerol and $0.03 \%$ bromophenol blue) co-polymerized with $0.1 \%$ gelatin as a substrate. After completing electrophoresis, gels were incubated for $1 \mathrm{~h}$ at $37^{\circ} \mathrm{C}$ in a $2.5 \%$ Triton X-100 solution, washed in $50 \mathrm{mM}$ Tris- $\mathrm{HCl}$ buffer (pH 7.5) for $30 \mathrm{~min}$ and incubated for another $20 \mathrm{~h}$ in $50 \mathrm{mM}$ Tris- $\mathrm{HCl}$ buffer $(\mathrm{pH}$ 7.5) containing $200 \mathrm{mM} \mathrm{NaCl}, 10 \mathrm{mM} \mathrm{CaCl}_{2}$ and $0.05 \%$ Brij35. The gels were stained with a solution containing $0.1 \%$ Coomassie Brilliant Blue G-250, 2\% acetic acid and 45\% methanol and then destained in a solution with $30 \%$ methanol and $10 \%$ acetic acid.

\section{Statistical Analysis}

The data are presented as mean \pm s.e.m for each treatment group in the in vivo and in vitro experiments. Statistical analyses were conducted using a Statistical Analysis Systems program (SAS Institute, Cary, NC, USA). One-way ANOVA was used to determine inhibitory effects of kaempferol on airway fibrosis in epithelial cells and sensitized mice. Differences among treatment groups were analyzed with Duncan's multiple-range test and were considered to be significant at $P<0.05$.

\section{RESULTS}

\section{Suppression of LPS- and OVA-Triggered Induction of TGF- $\beta 1$ by Kaempferol}

Asthma has been strongly associated with increased expression of TGF- $\beta 1$ in the airway, and TGF- $\beta$ is a principle mediator of airway fibrosis. ${ }^{9,10}$ This study investigated whether TGF- $\beta$ was involved in LPS-instigated airway remodeling, which was deterred by kaempferol. When LPS were solely applied to BEAS-2B cells, cellular expression of TGF- $\beta 1$ was enhanced (Figure 1a). In contrast, $1-20 \mu \mathrm{M}$ kaempferol lessened LPS-augmented cellular levels of TGF- $\beta 1$ in a dose-dependent manner. In addition, it was found that TGF- $\beta$ RI and TGF- $\beta$ RII were significantly induced by LPS stimulation, which was dose-dependently reversed by 1-20 $\mu \mathrm{M}$ kaempferol (Figure 1a). Accordingly, LPS can cause airway fibrosis by inducing profibrotic TGF- $\beta 1$ in the airway epithelium. The TGF- $\beta 1$ induction was minimal in the lung tissues of control mice, whereas in OVA-challenged mice its tissue level was markedly enhanced (Figure 1b). However, the oral administration of kaempferol at 10 or $20 \mathrm{mg} / \mathrm{kg}$ BW to OVA-challenged mice encumbered pulmonary TGF- $\beta 1$ induction. The western blotting data revealed that kaempferol deterred TGF- $\beta$ RI from inducing in lung tissues of OVA-challenged mice (Figure 1b).

\section{Blockade of Airway EMT by Kaempferol}

TGF- $\beta$ would trigger signaling cascades in epithelial cells that lead to a change from an epithelial to a mesenchymal phenotype. It has been considered that the loss of the epithelial marker E-cadherin and the induction of the mesenchymal marker $\mathrm{N}$-cadherin are fundamental events in EMT. ${ }^{25}$
BEAS-2B cells exposed to $10 \mathrm{ng} / \mathrm{ml}$ TGF- $\beta$ up to $72 \mathrm{~h}$ induced a change of morphology consistent with EMT and cellular N-cadherin (brown staining, Figure 2a). When 1$20 \mu \mathrm{M}$ kaempferol was added to epithelial cells in the presence of TGF- $\beta$, the EMT process was disturbed with concurrent diminution of cellular $\mathrm{N}$-cadherin induction (Figure 2a). Kaempferol substantially increased epithelial E-cadherin expression dampened by TGF- $\beta$ (Figure 2b). Thus kaempferol may improve epithelial barrier function by cell-cell adhesion and structural polarization lost in the EMT process. Consistently, OVA inhalation to mice led to diminished levels of the epithelial marker E-cadherin (green staining in mouse airway), which was reversed by oral administration of kaempferol (Figure 2c). In OVA-challenged mice, there was a marked increase in airway resident cells and epithelial thickening observed (blue DAPI staining).

This study also determined whether LPS and TGF- $\beta$ promoted cellular expression of $\alpha$-SMA typical in EMT, which was demoted by kaempferol. $\alpha$-SMA is commonly used as a marker of myofibroblast generation in EMT. The expression of EMT marker $\alpha$-SMA was elevated up to $72 \mathrm{~h}$ following TGF- $\beta$ stimulation of BEAS-2B cells (Figure 3a). Kaempferol at the doses of $1-20 \mu \mathrm{M}$ dose-dependently diminished the elevated $\alpha$-SMA expression in $72 \mathrm{~h}$-TGF- $\beta$-exposed BEAS-2B cells (Figure $3 b$ ). Similarly, $\alpha$-SMA upregulated in LPS-treated epithelial cells (myofibroblasts) was lessened by kaempferol (Figure 3c). Consistent with the induction airway epithelial $\alpha$-SMA by LPS or TGF- $\beta$, the OVA challenge caused myofibroblast formation, as manifested by the reddish staining in mouse airway wall with an immunofluorescent Cy3 dye conjugated to anti- $\alpha$-SMC (Figure $3 d$ ). This airway EMT was diminished by orally treating with $\geq 10 \mathrm{mg} / \mathrm{kg}$ kaempferol. Accordingly, kaempferol may reverse endotoxininstigated airway EMT leading to fibrosis.

\section{Inhibition of Asthmatic Induction of Collagen IV by Kaempferol}

Subepithelial fibrosis in the airways entails increased ECM deposition by myofibroblasts and submucosal resident fibroblasts and fibrocytes expressing profibrotic cytokines. ${ }^{5,6}$ Fibrogenic collagen deposition are important pathophysiological components of airway remodeling in chronic asthma. The epithelial production of collagen IV was boosted in BEAS-2B cells exposed to LPS and such secretion was suppressed by adding 1-20 $\mu \mathrm{M}$ kaempferol (Figure 4a). Similar effects on collagen IV secretion were observed with TGF- $\beta$ (data not shown). The lung tissue level of fibrogenic collagen IV increased in mice sensitized and stimulated with $5 \%$ OVA (Figure $4 \mathrm{~b}$ ). When 10 or $20 \mathrm{mg} / \mathrm{kg}$ BW kaempferol was administrated to OVA-challenged mice, the enhanced collagen IV production was significantly reduced.

This study further investigated that kaempferol ameliorated the structural remodeling of airways due to increased deposition of ECM components. Collagen fiber deposition was notably observed (blue color) in lung tissues of 
a
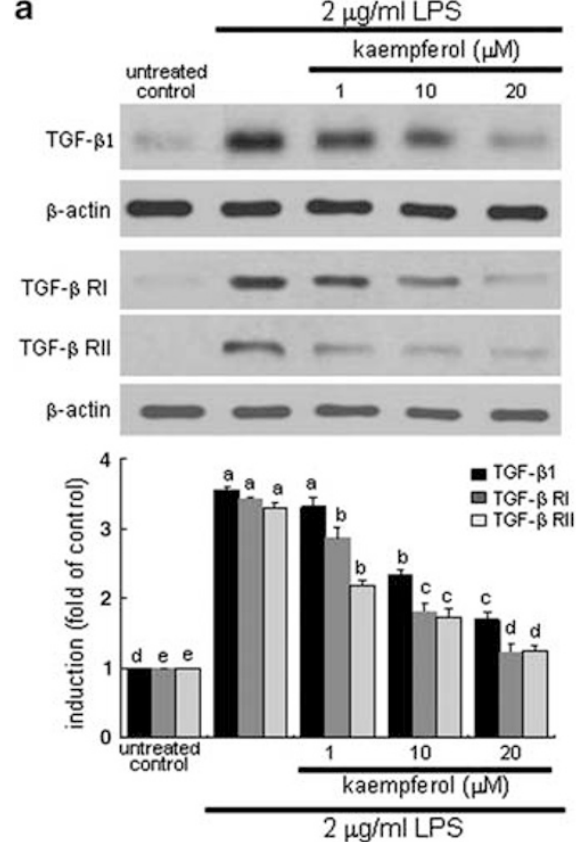

b
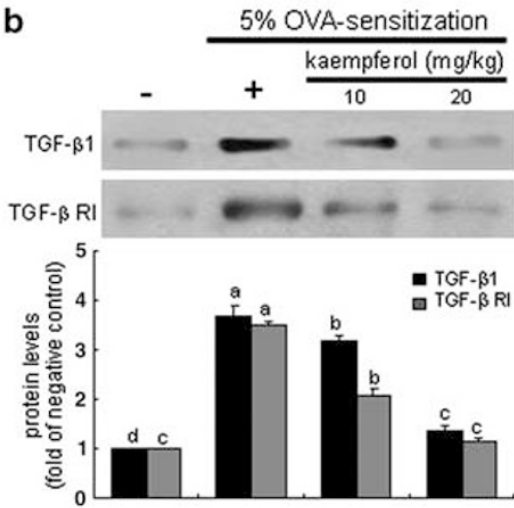

Figure 1 Inhibitory effects of kaempferol on induction of TGF- $\beta 1$ and TGF- $\beta$ RI and RII in BEAS-2B cells exposed to LPS (a) and in OVA-challenged mouse lung tissues (b). After culturing, cells were treated with 1-20 $\mu \mathrm{M}$ kaempferol and simulated with $2 \mu \mathrm{g} / \mathrm{ml}$ LPS for $72 \mathrm{~h}$. Cell lysates and tissue extracts were subjected to 8 and 12\% SDS-PAGE and western blotting analysis with a primary antibody against TGF- $\beta 1$, TGF- $\beta$ RI and TGF- $\beta$ RII. Representative blot data were obtained from four experiments, and $\beta$-actin protein was used as an internal control. The bar graphs (mean \pm s.e.m.) in the bottom panels represent quantitative results of blots. Values not sharing a common letter are significantly different at $P<0.05$.

OVA-challenged mice, evidenced by Masson's trichrome staining of lung tissue sections (Figure 4c). There was dense deposition of collagen fibers around the bronchi in lung tissues of OVA-challenged mice. On the contrary, the treatment with 10 or $20 \mathrm{mg} / \mathrm{kg}$ kaempferol reduced the collagen fiber deposition and alleviated subepithelial fibrosis (Figure 4c). It should be noted that OVA sensitization and stimulation induced epithelial cell modulation and goblet cell hyperplasia (red color).

\section{Suppressive Effect of Kaempferol on LPS- or OVA- Promoted MMP Production}

Increased levels of ECM component and MMP production arise from EMT induced by growth factors like TGF- $\beta$ and fibroblast growth factor-2. ${ }^{26}$ LPS upregulated the epithelial expression of MT1-MMP, whereas the cellular induction of TIMP-2 in epithelial cells was demoted in the presence of LPS (Figure 5a). Accordingly, the specific MMP inhibition would be an appropriate target for therapeutic intervention in asthmatic EMT and fibrosis. It was also found that the LPSand TGF- $\beta$-enhanced MT1-MMP expression was abolished by treating BEAS-2B cells with $20 \mu \mathrm{M}$ kaempferol (Figures $5 \mathrm{a}$ and $\mathrm{b}$ ). On the contrary, kaempferol boosted TIMP-2 expression in BEAS-2B cells exposed to LPS and TGF- $\beta$.

The active MMP-2 level was markedly elevated within $24 \mathrm{~h}$ after initiating LPS episode of BEAS-2B cells and thereafter progressively diminished (Figure $5 \mathrm{c}$ ). However, kaempferol dose-dependently dampened the gelatinolytic MMP-2 activity elevated by $24 \mathrm{~h}$ treatment with LPS (Figure $5 \mathrm{~d}$ ).
Consistently, there was a heavy pinkish staining in the airway of OVA-inhaled mice, indicating that OVA challenge activated epithelial MMP-2 due to EMT (Figure 5e). The MMP-2 activation was subsided by orally treating with $\geq 10 \mathrm{mg} / \mathrm{kg}$ kaempferol. Accordingly, kaempferol may reverse endotoxininstigated airway EMT leading to fibrosis.

\section{Inhibitory Effect of Kaempferol on LPS- or OVA- Promoted PAR-1 Induction}

PAR activation throughout the airways may modulate bronchomotor tone and produce goblet metaplasia in respiratory tract disorders and fibrotic diseases. ${ }^{12}$ PAR-1 is the signal-transducing receptor activated by serine proteinases, such as thrombin and trypsin. ${ }^{13}$ The PAR-1 expression was very weak in untreated quiescent cells, whereas the PAR-1 induction was strikingly elevated by a 48 -h incubation of $10 \mathrm{ng} / \mathrm{ml}$ TGF- $\beta$ with human BEAS-2B cells (Figures $6 \mathrm{a}$ and b). In contrast, $\geq 10 \mu \mathrm{M}$ kaempferol suppressed the PAR-1 expression promoted by adding TGF- $\beta$ (Figure $6 \mathrm{~b}$ ). The immunocytochemical analysis revealed the localization of cellular PAR- 1 in TGF- $\beta$-stimulated BEAS-2B cells. There was lack of cell membrane staining in the untreated cells control (Figure 6c). However, in TGF- $\beta$-stimulated BEAS-2B cells for $48 \mathrm{~h}$ heavy pinkish staining was observed outside blue colored-nuclei. The pinkish staining for the PAR-1 induction was substantially and dose-dependently diminished in cells supplemented with kaempferol (Figure 6c). Furthermore, the LPS episode highly enhanced the PAR-1 expression of 

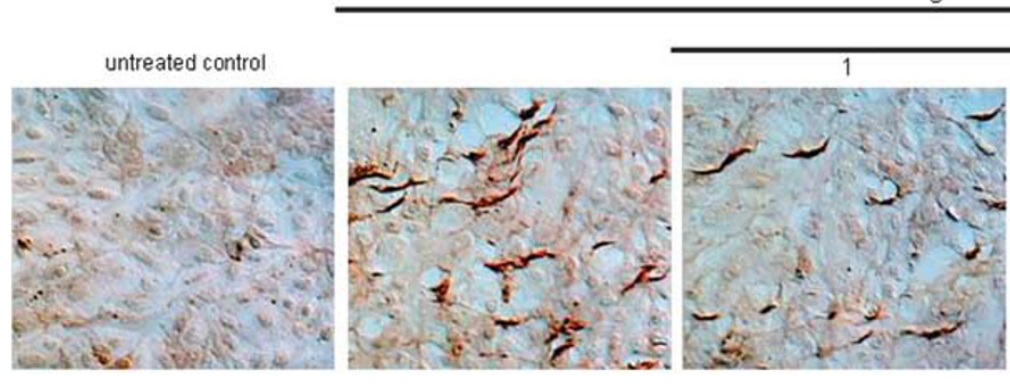

kaempferol $(\mu \mathrm{M})$

10

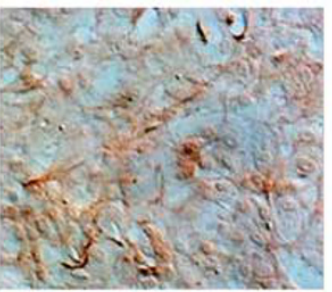

20

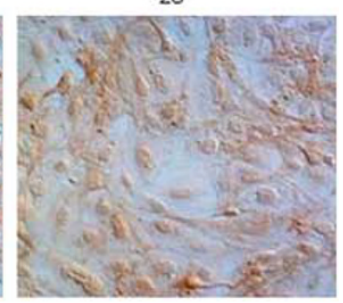

c
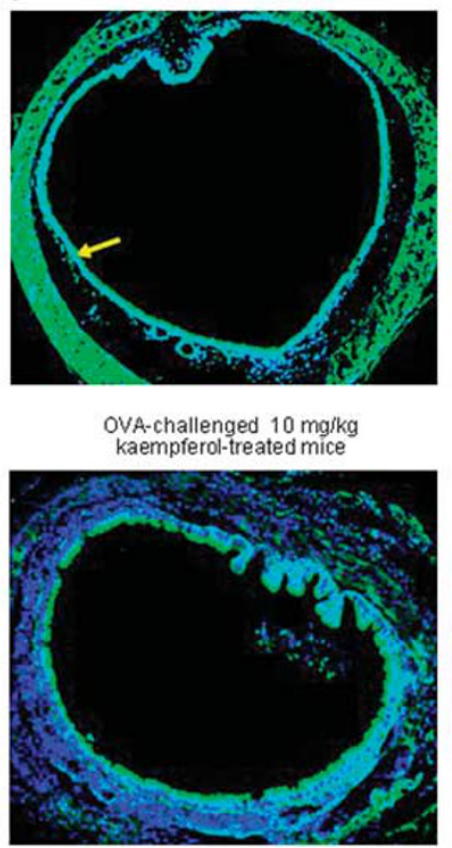

$10 \mathrm{ng} / \mathrm{ml}$ TGF- $\beta$

b
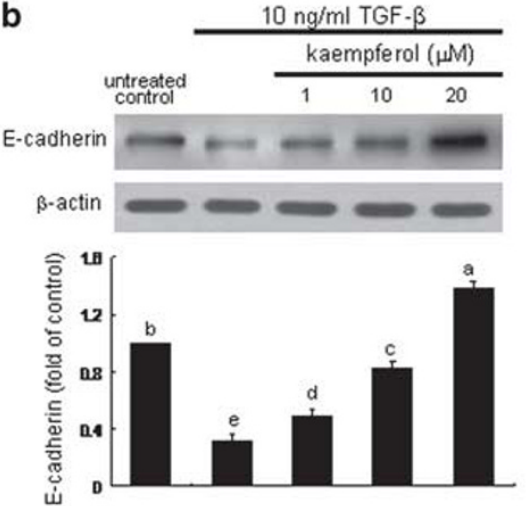

Figure 2 Inhibition of $\mathrm{N}$-cadherin induction (a) and upregulation of E-cadherin expression ( $\mathbf{b}$ and $\mathbf{c}$ ) in TGF- $\beta$-treated BEAS-2B cells by kaempferol. BEAS- $2 \mathrm{~B}$ cells were grown to $90 \%$ confluence and then stimulated with $10 \mathrm{ng} / \mathrm{ml} \mathrm{TGF-} \beta$ in the absence and presence of 1-20 $\mu \mathrm{M}$ kaempferol for $72 \mathrm{~h}$. Immunocytochemical analysis showing inhibition of $\mathrm{N}$-cadherin induction by kaempferol (a). Mesenchymal $\mathrm{N}$-cadherin identified as brown staining was visualized with a chromogen DAB. Microphotographs were taken with bright field illumination using an optical microscope AXIOIMAGER. Cell lysates and tissue extracts were subjected to $12 \%$ SDS-PAGE and western blotting analysis with a primary antibody against E-cadherin (b). $\beta$-Actin protein was used as an internal control. The bar graphs (mean \pm s.e.m., $n=4$ ) in the bottom panel represent quantitative results of blots obtained from a densitometer. Values not sharing a common letter are significantly different at $P<0.05$. Immunofluorescence analysis showing enhancement of E-cadherin induction in OVA-challenged mouse trachea tissues by kaempferol (c). Epithelial E-cadherin identified as green staining (arrow) was visualized with a FITC-conjugated secondary antibody, and nuclear staining was done with DAPI. Each photograph is representative of four mice. Original magnification: $\times 200$.

BEAS-2B cells, which was dose-dependently deterred by kaempferol (Figure 6d). In OVA-challenged mouse airways, the enhanced PAR-1 was near-completely abolished by oral administration of $20 \mathrm{mg} / \mathrm{kg}$ kaempferol (Figure 6e). Thus PAR-1 would be involved in the contribution of airway epithelial cells to the development of airway fibrosis by release of pro-inflammatory mediators like TGF- $\beta$.

\section{Inhibitory Effect of Kaempferol on LPS- or OVA- Promoted PAR-1 Induction}

This study attempted to test whether the PAR-1 induction by LPS was mediated through activating TGF- $\beta$ signaling.
Similar to $20 \mu \mathrm{M}$ kaempferol, the TGF- $\beta$ RI inhibitor HTS 466284 dampened PAR-1 expression highly enhanced in LPSstimulated BEAS-2B cells for $48 \mathrm{~h}$. It can be speculated that the LPS induction of epithelial PAR-1 may be blunted by kaempferol by disturbing TGF- $\beta$ signaling (Figure 7a).

PAR-1 signaling is responsible for goblet cell metaplasia and emphysema induced by a chemoattractant and degranulating agent for neutrophils. ${ }^{27}$ This study elucidated that the EMT formation and fibrosis was regulated by PAR-1 activation. TGF- $\beta$-downregulated E-cadherin expression and TGF- $\beta$ induction of $\alpha$-SMA were reversed to the normal level in the presence of $2 \mu \mathrm{M}$ SCH 79797, a PAR-1 inhibitor 

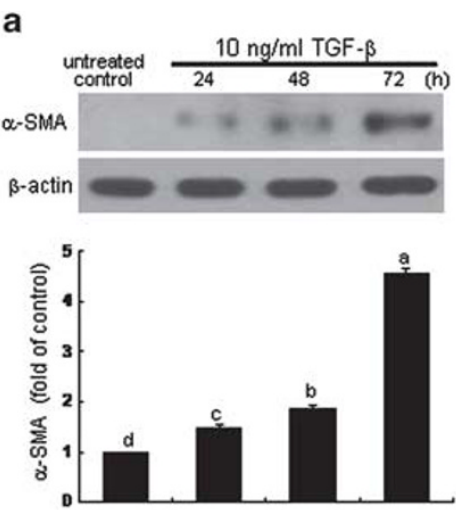

d

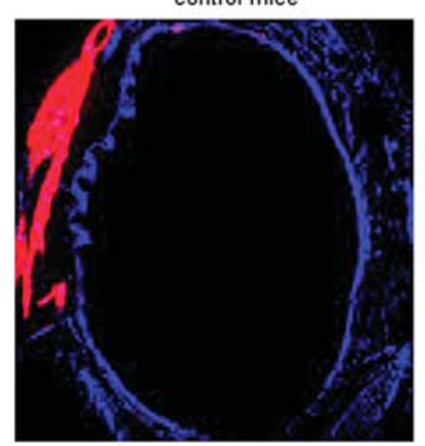

control mice b
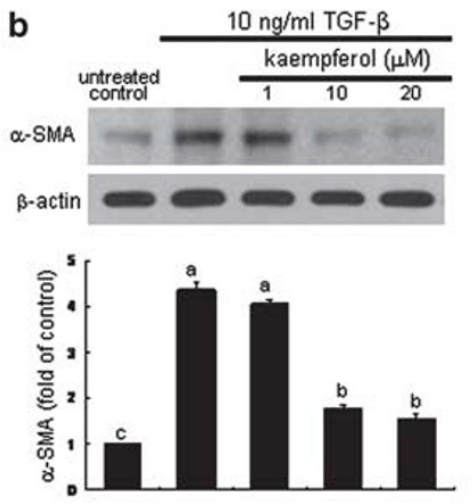

c
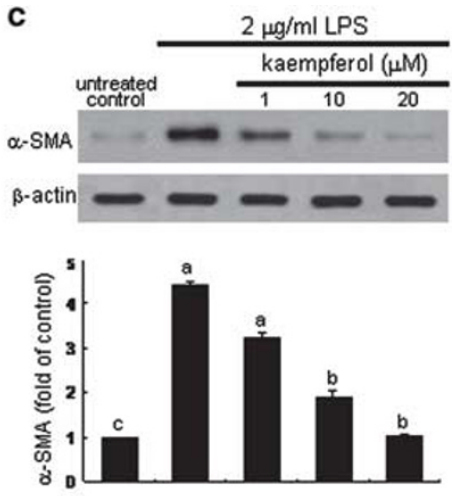

OVA-challenged mice

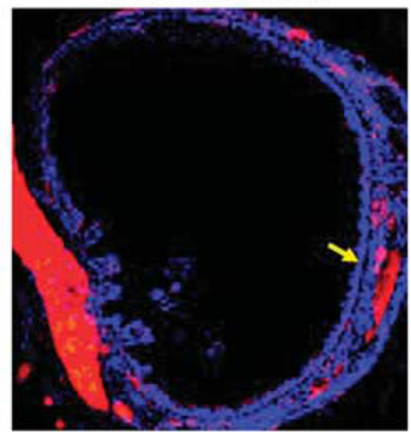

OVA-challenged $10 \mathrm{mg} / \mathrm{kg}$ kaempferol-treated mice

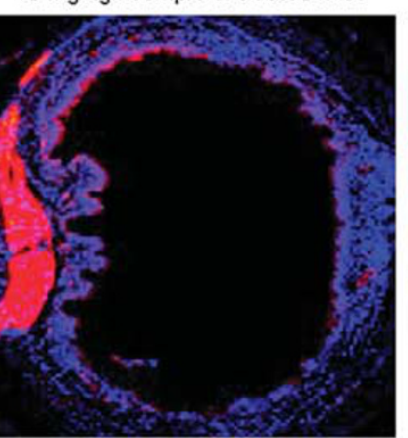

OVA-challenged $20 \mathrm{mg} / \mathrm{kg}$ kaempferol-treated mice

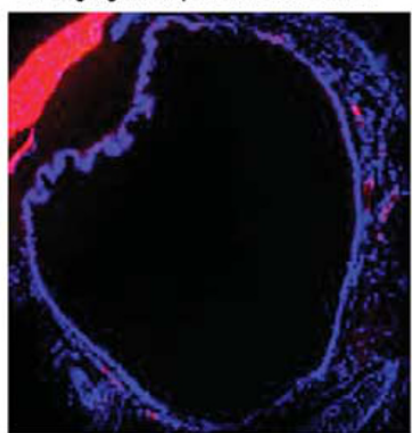

Figure 3 Western blotting analyses showing time course responses of $\alpha$-SMA expression (a) and inhibition of $\alpha$-SMA inductionin TGF- $\beta$ - (b) or LPSstimulated (c) BEAS-2B cells. After culturing cells with $10 \mathrm{ng} / \mathrm{ml} \mathrm{TGF}-\beta$ (a and $\mathbf{b}$ ) or $2 \mu \mathrm{g} / \mathrm{ml}$ LPS (c) in the absence and presence of $1-20 \mu \mathrm{M}$ kaempferol for $72 \mathrm{~h}$, cell extracts were subjected to $8 \%$ SDS-PAGE and western blotting analysis with a primary antibody against $\alpha$-SMA. $\beta$-Actin protein was used as an internal control. The bar graphs (mean \pm s.e.m., $n=4$ ) in the bottom panel represent quantitative results of blots obtained from a densitometer. Values not sharing a common letter are significantly different at $P<0.05$. Immunofluorescence analysis showing inhibition of $\alpha$-SMA induction in OVAchallenged mouse trachea tissues by kaempferol (d). $\alpha$-SMA identified as red staining (arrow) was visualized with a Cy3-conjugated secondary antibody, and nuclear staining was done with DAPI. Each photograph is representative of four mice. Original magnification: $\times 200$.

(Figure 7b). Similar restoration was observed in collagen IV production in epithelial cells treated with $2 \mu \mathrm{M} \mathrm{SCH} 79797$ or $20 \mu \mathrm{M}$ kaempferol (Figure $7 \mathrm{~b}$ ). The EMT formation and fibrosis encumbered by kaempferol was most likely attributed to PAR-1 signaling.

\section{DISCUSSION}

Six major findings were extracted from this study. (1) The viability of BEAS-2B cells was not influenced by treating with $\leq 20 \mu \mathrm{M}$ kaempferol. ${ }^{20}$ Nontoxic kaempferol at $1-20 \mu \mathrm{M}$ suppressed epithelial induction of TGF- $\beta 1$ and its receptors by LPS. (2) TGF- $\beta 1$ was highly induced in OVA-challenged lung tissue, which was dampened by kaempferol. (3) Kaempferol deterred myofibroblast formation due to TGF- $\beta$-triggered EMT, concurrently inducing epithelial $\mathrm{E}$-cadherin and inhibiting induction of $\mathrm{N}$-cadherin and $\alpha$-SMA. (4) Oral administration of kaempferol encumbered epithelial cell excrescence, transformation and thickening by diminishing E-cadherin and $\alpha$-SMA induction in OVA-challenged mouse airway. (5) The collagen IV induction and MT1-MMP production by LPS was attenuated by kaempferol, indicating that this compound retarded airway
EMT and fibrosis by disturbing TGF- $\beta$ pathway. (6) Kaempferol dampened EMT via disrupting TGF- $\beta$-PAR-1 signaling triggered by LPS. Accordingly, kaempferol alleviated endotoxin- or allergen-induced fibrotic airway remodeling through blunting bronchial EMT entailing TGF- $\beta$ and PAR-1 signaling.

Kaempferol (3,5,7-trihydroxy-2-(4-hydroxyphenyl)-4H-1benzopyran-4-one) is a flavonol-type flavonoid found in many edible plants (tea, broccoli, citrus fruits and apples) or botanical products commonly used in traditional medicine (Ginkgo biloba, Sophora japonica and propolis). Numerous pre-clinical studies have shown that kaempferol exerts a wide range of pharmacological properties, such as antioxidant, anti-inflammatory, anti-cancer, cardioprotective, neuroprotective, anti-diabetic, anti-osteoporotic and anti-allergic activities. ${ }^{18}$ Flavonols of kaempferol and quercetin inhibit IgEmediated release of pro-inflammatory IL- 6 , IL- 8 and TNF- $\alpha$ from mast cells possibly through inhibition of intracellular calcium influx and PKC theta signaling, being suitable for the treatment of allergic and inflammatory diseases. ${ }^{28}$ Our recent studies have demonstrated that kaempferol suppresses eosionphil infiltration and airway inflammation in airway epithelial cells and in mice with allergic asthma. ${ }^{20,21}$ The 
a
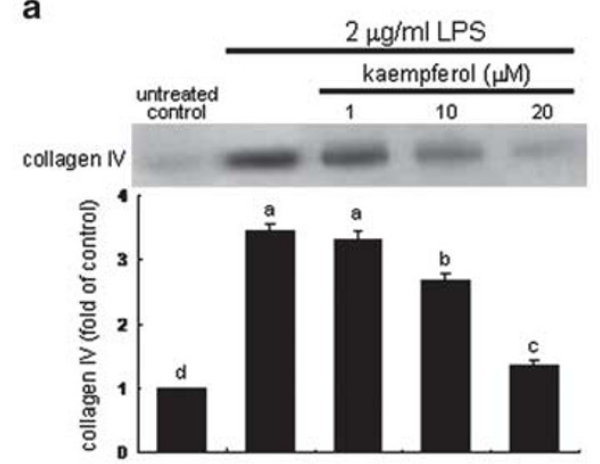

b
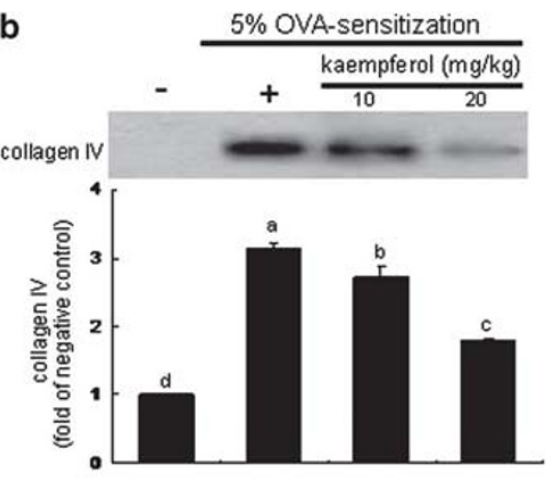
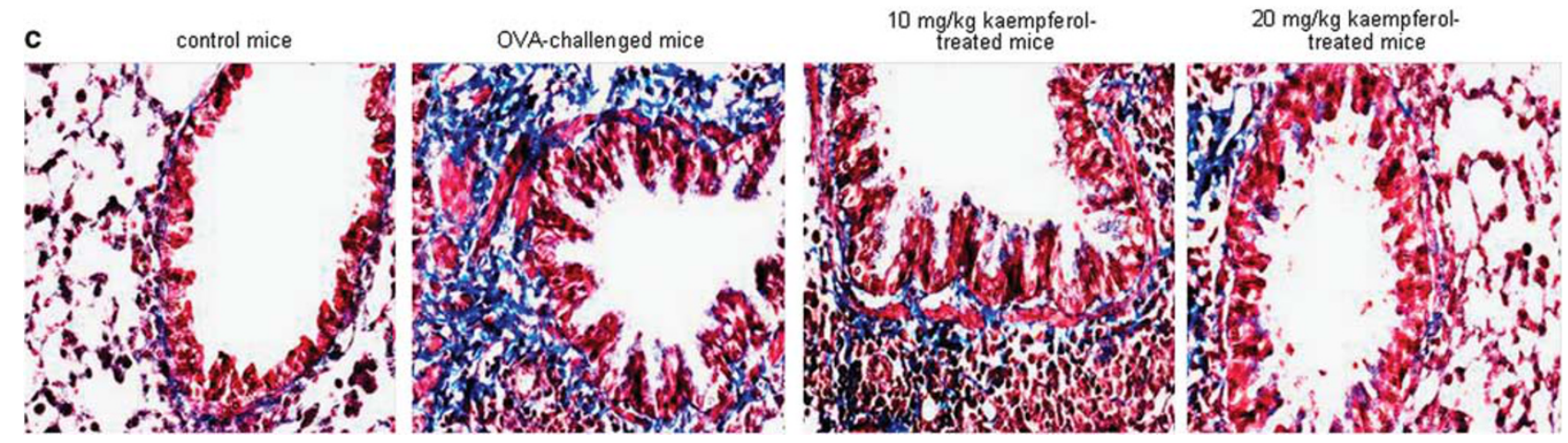

Figure 4 Suppressive effects of kaempferol on collagen IV production and lung fibrosis in BEAS-2B cells exposed to LPS and in OVA-sensitized mice. Tissue extracts were subjected to western blotting analysis with anti-collagen IV (a and $\mathbf{b}$ ). The bar graphs (mean \pm s.e.m., $n=4$ ) in the bottom panels represent quantitative desitometric results. Values not sharing a common letter are significantly different at $P<0.05$. Pathological collagen IV changes in lung fibrosis in different mouse groups observed by Masson trichrome staining (c). The collagen fibers were stained in blue.

current study further investigated whether kaempferol inhibited airway fibrosis responsible for the structural remodeling of airways. It has been well accepted that high expression of TGF- $\beta$ is observed and has an essential role in airway remodeling in asthmatic patients. ${ }^{10}$ LPS and OVA inhalation induced TGF- $\beta 1$-receptor signaling in respective epithelial cells and airway tissues, which was blocked by kaempferol. Nevertheless, the cellular origin of this cytokine in the asthmatic airways is still a contemporaneous debate. ${ }^{29}$

Airway fibrosis entails epithelial cell modulation, smooth muscle thickening and increased deposition of matrix proteins, such as collagens. ${ }^{1-3}$ The polyphenol resveratrol reduces subepithelial collagen deposition with concomitant airway hyper-reactivity. ${ }^{23} \mathrm{~A}$ cyclic terpene limonene found in lemon and other citrus fruits inhibits airway smooth muscle thickness and goblet cell and smooth muscle metaplasia in dermatophagoides farinae-treated mice. ${ }^{24}$ Administration of Skullcapflavone II suppresses subepithelial collagen deposition and goblet cell hyperplasia by acting on TGF$\beta 1 /$ Smad signaling pathways. ${ }^{30}$ Similarly, stragalus extract and budesonide reduces allergen-induced increase in the thickness of bronchial airway, goblet cell hyperplasia and collagen deposition via TGF- $\beta 1 /$ Smad signaling pathways. ${ }^{31}$ This study revealed that kaempferol retarded the expression of profibrotic proteins of collagen IV upregulated in LPS- or TGF- $\beta$-exposed airway epithelial cells. Also, oral administration of kaempferol reduced lung tissue level of collagen IV of OVA-inhaled mice and encumbered the deposition of collagen fibers in the airways. Accordingly, kaempferol may be a therapeutic drug antagonizing airway fibrosis for the treatment of patients with a severe asthmatic airway.

Fibrosis results from excessive ECM deposition by myofibroblasts in the pathogenic course such as chronic inflammation and wound healing in many organs such as kidneys, lung and liver. EMT is widely considered to be a crucial process in fibrosis and is suggested as a possible mechanism for the generation of myofibroblast that contribute to fibrosis. Growth factors like TGF- $\beta$ can trigger EMT typical of loss of epithelial markers, acquisition of mesenchymal markers and increased levels of ECM component. ${ }^{8,26}$ This study found that kaempferol suppressed TGF- $\beta$-triggered EMT and myofibroblast formation with concomitant restoration of E-cadherin expression, expression reduction of $\mathrm{N}$-cadherin and $\alpha$-SMA and ECM component deposition. Consistently, oral administration of kaempferol to mice restored the diminished E-cadherin level and lessened the enhanced $\alpha$-SMA level in OVA-challenged mouse airways. Likewise, natural propolis extracts inhibit TGF- $\beta 1$-induced EMT in alveolar epithelial A549 cells, inhibiting progressive cell morphological changes and decreased E-cadherin. ${ }^{32}$ Moreover, kaempferol dampened epithelial cell excrescence, 
a
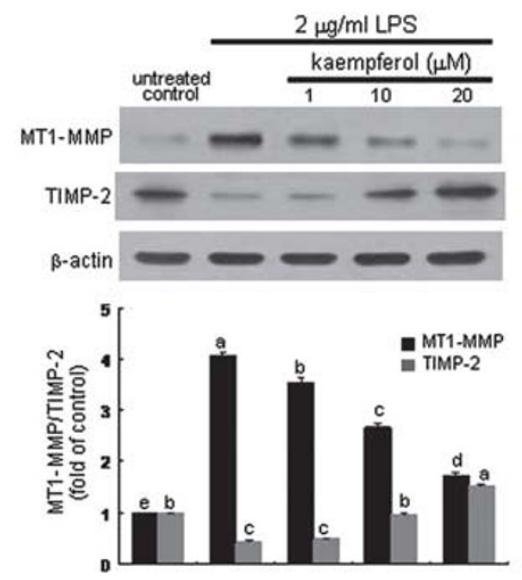

b
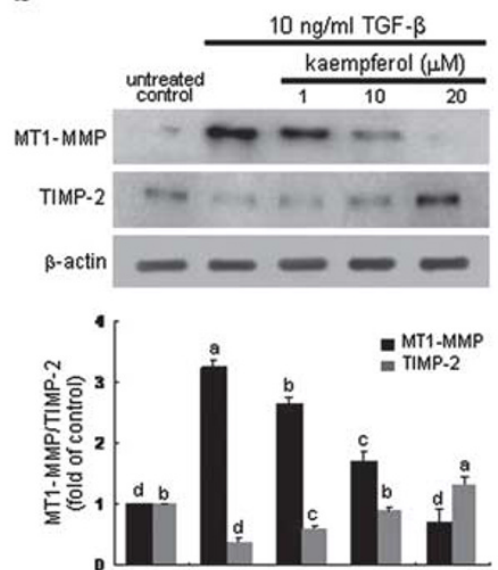

c

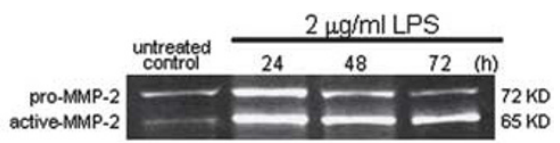

d

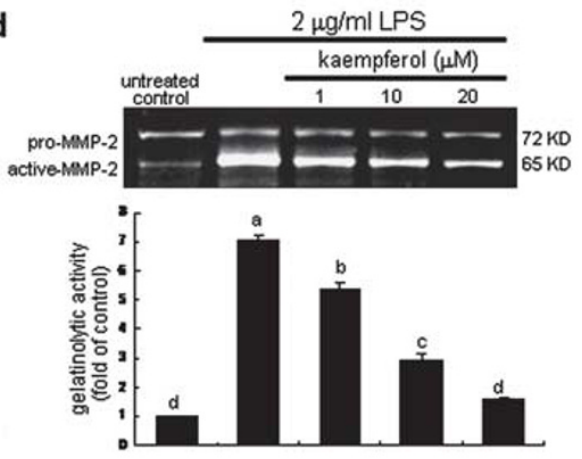

e

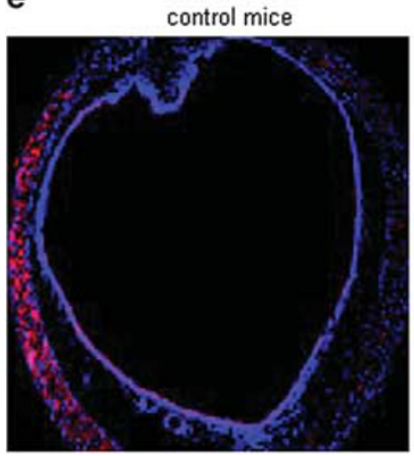

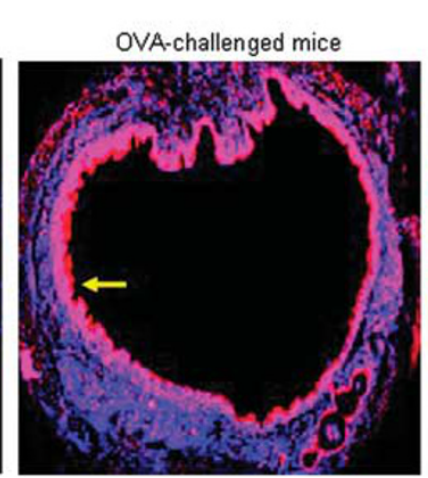

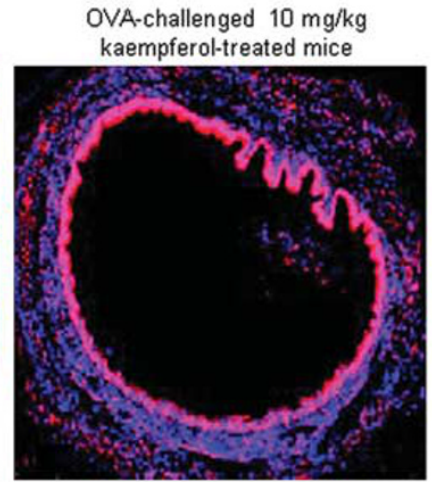

OVA-challenged $20 \mathrm{mg} / \mathrm{kg}$ kaempferol-treated mice

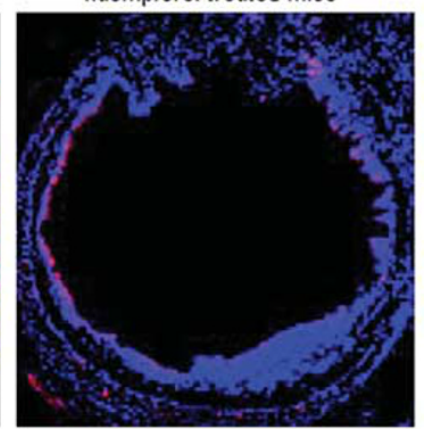

Figure 5 Inhibition of induction of MT1-MMP and TIMP-2 ( $\mathbf{a}$ and $\mathbf{b}$ ) and activity (c and $\mathbf{d}$ ) of MMP-2 in BEAS-2B cells treated with kaempferol and exposed to $2 \mu \mathrm{g} / \mathrm{ml}$ LPS or $10 \mathrm{ng} / \mathrm{ml}$ TGF- $\beta$ for $72 \mathrm{~h}$. After BEAS-2B culture protocols, western blotting analysis with cell lysates were conducted with a primary antibody against MT1-MMP and TIMP-2 (a and $\mathbf{b})$ ). $\beta$-Actin protein was used as an internal control. Gelatin zymograpy data showing epithelial MMP-2 activity (c and $\mathbf{d})$. For MMP-2 gelatin zymography, collected culture media were run for electrophoresis on 8\% SDS-PAGE copolymerized with $0.1 \%$ gelatin as the substrate (four separate experiments). The bar graphs (mean \pm s.e.m., $n=4$ ) in the bottom panel represent quantitative results obtained from a densitometer. Values not sharing a common letter are significantly different at $P<0.05$. Immunohistological analysis showing inhibition of MMP-2 activation in OVA-challenged mouse trachea tissues by kaempferol (e). Epithelial active MMP-2 identified as pinkish (arrow) was visualized with a Cy3-conjugated secondary antibody, and nuclear staining was done with DAPI. Each photograph is representative of four mice. Original magnification: $\times 200$.

goblet cell hyperplasia and smooth muscle thickening in OVA-challenged mice. In asthma, the mucosal barrier function can be damaged due to disrupted expression of E-cadherin. ${ }^{33}$ Accordingly, kaempferol may be effective in preserving the barrier function of airway epithelium by enhancing E-cadherin level.

MMP-9 and TIMP-1 have been shown to have a pivotal role in asthmatic airway remodeling, which explain the progressive subepithelial fibrosis and structural changes in the ECM. ${ }^{34,35}$ MMP can be produced during EMT process by triggering signaling cascades in epithelial cells by TGF- $\beta$ and other factors. ${ }^{8,26}$ Kaempferol attenuated MT1-MMP expression with concurrent TIMP-2 induction in TGF- $\beta$ induced epithelial cells. The cell surface MT1-MMP interacting with TIMP-2 activates MMP-2 protein that has a major role in the ECM remodeling. ${ }^{36}$ Similar to the specific kaempferol inhibition of MMP-2 activation by LPS, the in vivo study in mice revealed that oral administration of kaempferol abrogated the MMP-2 induction by OVA inhalation. Luteolin and quercetin prevent the occurrence of overexpression of MMP-9 that results in induction of the EMT in epidermal carcinoma cells. ${ }^{37}$

The regulatory mechanisms involved in EMT and epithelial fibrosis would help determine effective therapies to halt the progression of airway remodeling in asthma. PAR-1 is an important player in the development of pulmonary fibrosis and PAR-2 contributes to allergic airway inflammation. ${ }^{14}$ An understanding of PAR-induced cellular events and the significance of receptor blockade may help in the development of novel therapeutic strategies protecting lung destruction. PAR-1 is reported to be a receptor of MMP-1 that regulates the PAR-1 activation through its cleavagetethered intracellular signaling. ${ }^{38}$ Another investigation has shown that the lack of PAR-1 signaling protects the bacterial chemotactic peptide formyl-methionyl-leucyl-phenylalanineinduced goblet cell metaplasia and emphysema in mice. ${ }^{27}$ 
a

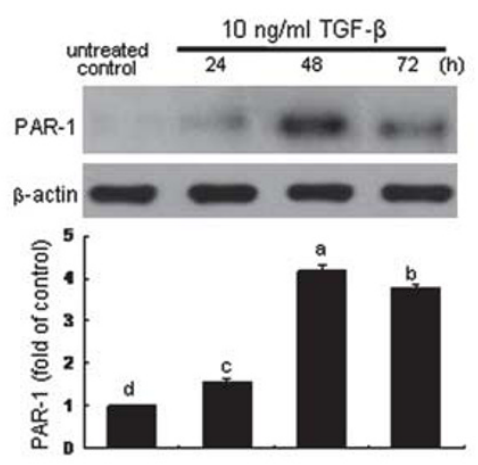

b

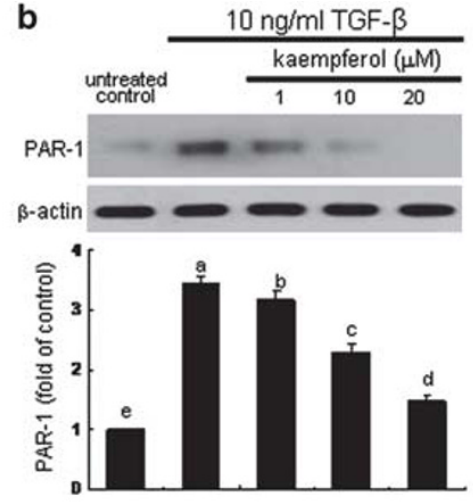

C $10 \mathrm{ng} / \mathrm{ml}$ TGF- $\beta$
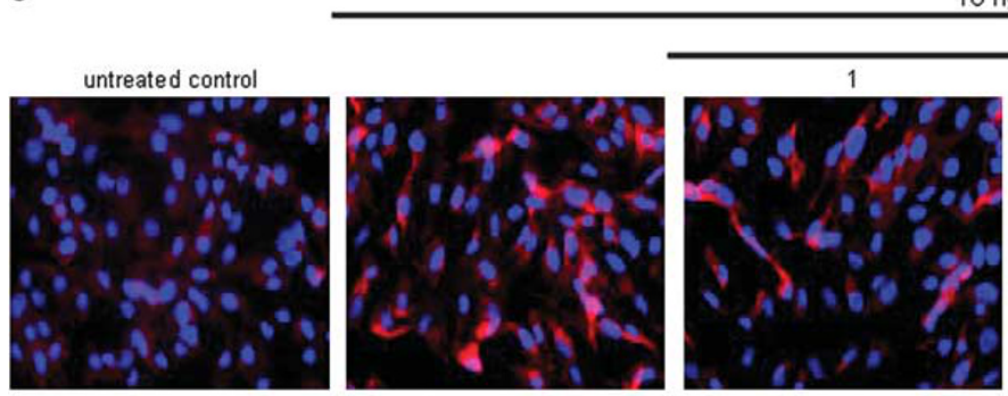

kaempferol $(\mu \mathrm{M})$
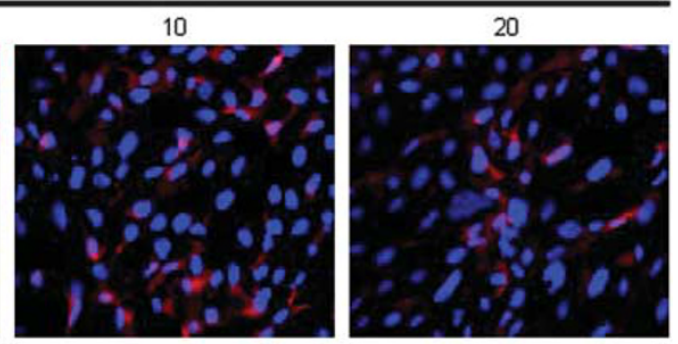

d
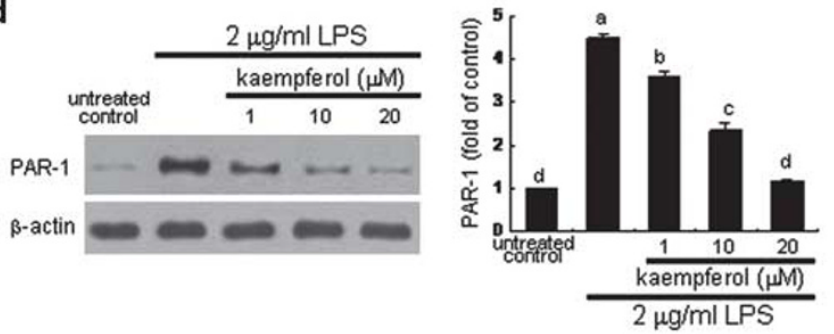

e
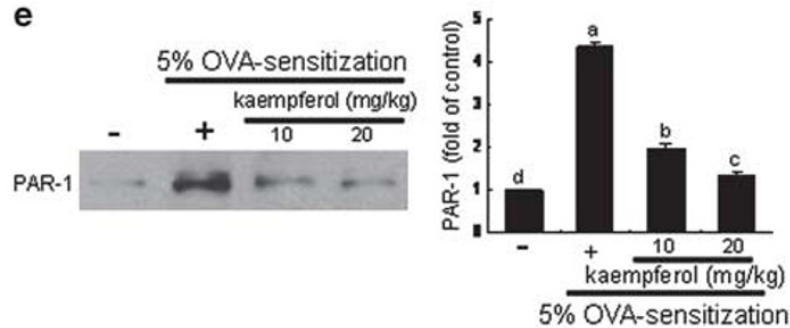

Figure 6 Temporal induction of PAR-1 (a) and its blockade by kaempferol in TGF- $\beta$ - (b and $\mathbf{c}$ ) or LPS- exposed epithelial cells (d) and in OVA-

challenged mouse lung tissues (e). BEAS-2B cells were cultured with $10 \mathrm{ng} / \mathrm{ml} \mathrm{TGF-} \beta$ in the absence and presence of $1-20 \mu \mathrm{M}$ kaempferol for $72 \mathrm{~h}$. Cell lysates and tissue extracts were subjected to 8\% SDS-PAGE and western blotting analysis with a primary antibody against human PAR-1 (four separate experiments). $\beta$-Actin protein was used as an internal control. The bar graphs (mean \pm s.e.m., $n=4$ ) in the bottom panel represent quantitative results of blots obtained from a densitometer. Values not sharing a common letter are significantly different at $P<0.05$. Immunofluorescence analysis showing inhibition of PAR-1 expression in TGF- $\beta$-exposed epithelial cells by kaempferol (c). PAR-1 localization identified as red staining was visualized with a Cy3-conjugated secondary antibody. Nuclear staining was done with DAPI. Each photograph was representative of four mice. Original magnification: $\times 200$.

Also, the in vivo treatment with LPS in rats strongly increases the bronchorelaxant effect of PAR-2 activation. ${ }^{17}$ Thus, PAR1 and PAR-2 represent exciting targets for clinical intervention in epithelial fibrotic diseases. A recent study showed that PAR-1 and PAR-3 drive EMT of alveolar epithelial cells and have a potential role in lung fibrosis. ${ }^{39}$ Kaempferol inhibited the induction of PAR- 1 due to TGF- $\beta$ signaling responsive to LPS. Like $20 \mu \mathrm{M}$ kaempferol, the specific PAR-1 inhibition restored E-cadherin induction and abolished $\alpha$-SMA induction and collagen IV production near-completely. Accordingly, kaempferol was a potent PAR1 antagonist to TGF- $\beta$-triggered EMT leading to fibrosis in the bronchial airway.

In summary, this study investigated the potential of kaempferol as a target for therapeutic strategies in preventing airway fibrotic diseases. Nontoxic kaempferol suppressed entotoxin-induced profibrotic TGF- $\beta 1$ responsible for EMT process causing loss of E-cadherin and induction of $\alpha$-SMA and collagen IV. Oral administration of kaempferol blocked OVA inhalation-induced epithelial cell excrescence, thickening and fibrosis by attenuating tissue levels of collagen and $\alpha$ SMA in mouse airways. Moreover, kaempferol encumbered the epithelial MT1-MMP induction due to EMT by TGF- $\beta$ and MMP-2 induction in airway epithelium exposed to OVA. Furthermore, kaempferol inhibited the induction of PAR-1 responsive to TGF- $\beta$ leading to EMT and airway fibrosis. Therefore, kaemepferol was effective in ameliorating epithelial damage and thickening and increased deposition of ECM components by disturbing TGF- $\beta$-PAR- 1 signaling in cellular or animal models of allergic asthma. 
a
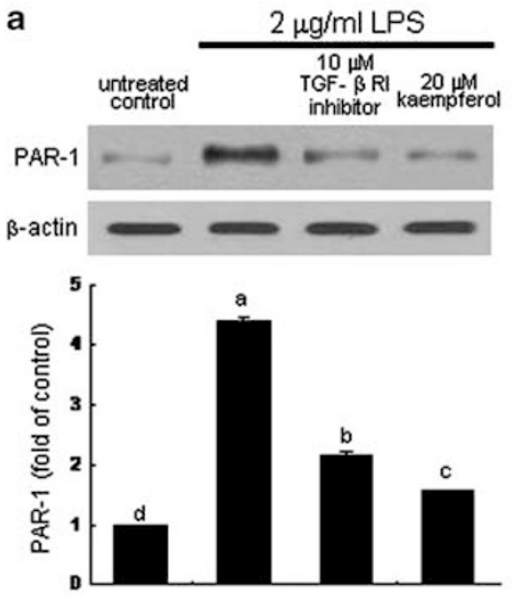

b

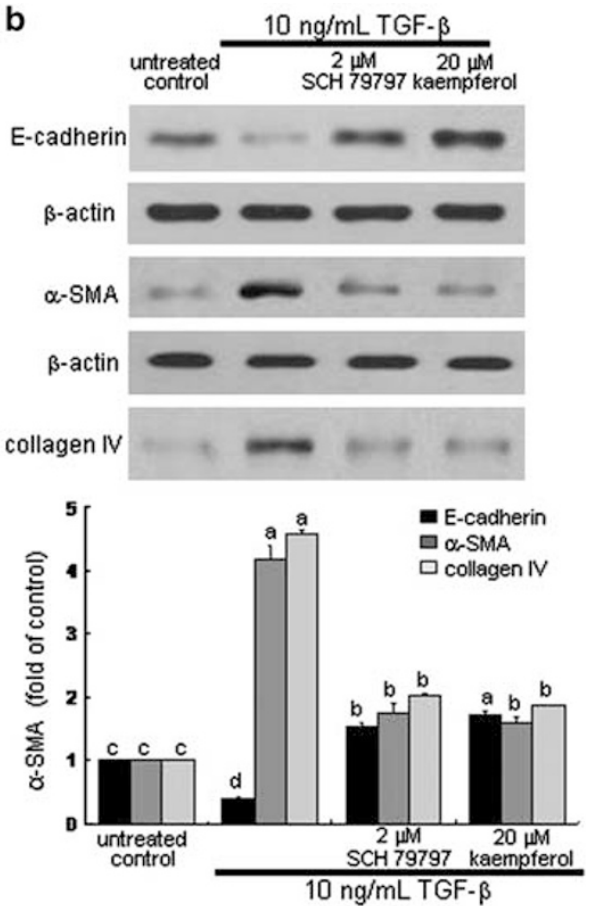

Figure 7 Western blotting analyses showing inhibition of PAR-1 induction by TGF- $\beta$-receptor blockade (a), and E-cadherin induction and inhibition of $\alpha$-SMA induction and collagen IV production by PAR-1 blockade (b). After culturing cells with $2 \mu \mathrm{g} / \mathrm{ml} \mathrm{LPS} \mathrm{or} 10 \mathrm{ng} / \mathrm{ml} \mathrm{TGF-} \beta$ in the absence and presence of 1-20 $\mu \mathrm{M}$ kaempferol, $2 \mu \mathrm{M}$ HTS 466284 (TGF- $\beta$ RI inhibitor), or $2 \mu \mathrm{M} \mathrm{SCH79797} \mathrm{(PAR-1} \mathrm{inhibition),} \mathrm{cell} \mathrm{extracts} \mathrm{were} \mathrm{subjected} \mathrm{to} 8$ and $12 \%$ SDS-PAGE and western blotting analysis with a primary antibody against PAR-1, E-cadherin, $\alpha$-SMA and collagen IV. $\beta$-Actin protein was used as an internal control. The bar graphs (mean \pm s.e.m., $n=4$ ) in the bottom panel represent quantitative results of blots obtained from a densitometer. Values not sharing a common letter are significantly different at $P<0.05$.

\section{ACKNOWLEDGMENTS}

This study was supported by the National Research Foundation of Korea (2012012946) and by the Regional Innovation Human Resources Fostering Grant funded by the National Research Foundation of Korea (2012-01-A-05003-12-010100).

\section{DISCLOSURE/CONFLICT OF INTEREST}

The authors declare no conflict of interest.

1. Davies DE. The role of the epithelium in airway remodeling in asthma. Proc Am Thorac Soc 2009;6:678-682.

2. Yamauchi K, Inoue H. Airway remodeling in asthma and irreversible airflow limitation-ECM deposition in airway and possible therapy for remodeling. Allergol Int 2007;56:321-329.

3. Munakata M. Airway remodeling and airway smooth muscle in asthma. Allergol Int 2006;55:235-243.

4. Carter RJ, Bradding P. The role of mast cells in the structural alterations of the airways as a potential mechanism in the pathogenesis of severe asthma. Curr Pharm Des 2011;17:685-698.

5. Olman MA. Epithelial cell modulation of airway fibrosis in asthma. Am J Respir Cell Mol Biol 2003:28:125-128.

6. Royce SG, Cheng V, Samuel CS, et al. The regulation of fibrosis in airway remodeling in asthma. Mol Cell Endocrinol 2012;351:167-175.

7. Hackett TL. Epithelial-mesenchymal transition in the pathophysiology of airway remodelling in asthma. Curr Opin Allergy Clin Immunol 2012;12:53-59.

8. Kalluri $R$, Weinberg RA. The basics of epithelial-mesenchymal transition. J Clin Invest 2009;119:1420-1428.

9. Duvernelle C, Freund V, Frossard N. Transforming growth factor-beta and its role in asthma. Pulm Pharmacol Ther 2003:16:181-196.

10. Halwani R, Al-Muhsen S, Al-Jahdali $\mathrm{H}$, et al. Role of transforming growth factor- $\beta$ in airway remodeling in asthma. Am J Respir Cell Mol Biol 2011;44:127-133.
11. Doerner AM, Zuraw BL. TGF-beta1 induced epithelial to mesenchymal transition (EMT) in human bronchial epithelial cells is enhanced by IL-1beta but not abrogated by corticosteroids. Respir Res 2009;10:100.

12. Peters T, Henry PJ. Protease-activated receptors and prostaglandins in inflammatory lung disease. Br J Pharmacol 2009;158:1017-1033.

13. Hansen KK, Oikonomopoulou K, Baruch A, et al. Proteinases as hormones: targets and mechanisms for proteolytic signaling. Biol Chem 2008;389:971-982.

14. Sokolova E, Reiser G. A novel therapeutic target in various lung diseases: airway proteases and protease-activated receptors. Pharmacol Ther 2007;115:70-83.

15. D'Agostino B, Roviezzo F, De Palma R, et al. Activation of proteaseactivated receptor-2 reduces airways inflammation in experimental allergic asthma. Clin Exp Allergy 2007;37:1436-1443.

16. Ebeling $\mathrm{C}$, Forsythe $\mathrm{P}, \mathrm{Ng} \mathrm{J}$, et al. Proteinase-activated receptor 2 activation in the airways enhances antigen-mediated airway inflammation and airway hyperresponsiveness through different pathways. J Allergy Clin Immunol 2005;115:623-630.

17. Morello S, Vellecco V, Roviezzo F, et al. A protective role for proteinase activated receptor 2 in airways of lipopolysaccharide-treated rats. Biochem Pharmacol 2005;71:223-230.

18. Calderón-Montaño JM, Burgos-Morón E, Pérez-Guerrero C, et al. A review on the dietary flavonoid kaempferol. Mini Rev Med Chem 2011:11:298-344.

19. Hannum SM. Potential impact of strawberries on human health: a review of the science. Crit Rev Food Sci Nutr 2004;44:1-17.

20. Gong JH, Shin D, Han SY, et al. Kaempferol suppresses eosionphil infiltration and airway inflammation in airway epithelial cells and in mice with allergic asthma. J Nutr 2012;142:47-56.

21. Gong JH, Shin D, Han SY, et al. Blockade of airway inflammation by kaempferol via disturbing tyk-stat signaling in airway epithelial cells and in asthmatic mice. Evid Based Complement Alternat Med 2013;2013:250725. 
22. Li N, Li Q, Zhou XD, et al. The effect of quercetin on human neutrophil elastase-induced mucin5AC expression in human airway epithelial cells. Int Immunopharmacol 2012;14:195-201.

23. Royce SG, Dang W, Yuan G, et al. Resveratrol has protective effects against airway remodeling and airway hyperreactivity in a murine model of allergic airways disease. Pathobiol Aging Age Relat Dis $2011 ; 1$.

24. Hirota $R$, Nakamura $H$, Bhatti SA, et al. Limonene inhalation reduces allergic airway inflammation in Dermatophagoides farinae-treated mice. Inhal Toxicol 2012;24:373-381.

25. Hackett TL, Warner SM, Stefanowicz D, et al. Induction of epithelialmesenchymal transition in primary airway epithelial cells from patients with asthma by transforming growth factor-beta1. Am J Respir Crit Care Med 2009;180:122-133.

26. Strutz F, Zeisberg M, Ziyadeh FN, et al. Role of basic fibroblast growth factor-2 in epithelial-mesenchymal transformation. Kidney Int 2002;61:1714-1728

27. Atzori L, Lucattelli M, Scotton CJ, et al. Absence of proteinaseactivated receptor-1 signaling in mice confers protection from fMLP-induced goblet cell metaplasia. Am J Respir Cell Mol Biol 2009;41:680-687.

28. Kempuraj D, Madhappan B, Christodoulou S, et al. Flavonols inhibit proinflammatory mediator release, intracellular calcium ion levels and protein kinase $\mathrm{C}$ theta phosphorylation in human mast cells. $\mathrm{Br}$ Pharmacol 2005;145:934-944.

29. Bossé Y, Rola-Pleszczynski M. Controversy surrounding the increased expression of TGF beta 1 in asthma. Respir Res 2007;8:66.

30. Jang HY, Ahn KS, Park MJ, et al. Skullcapflavone II inhibits ovalbumininduced airway inflammation in a mouse model of asthma. Int Immunopharmacol 2012;12:666-674.
31. $\mathrm{Qu} \mathrm{ZH}$, Yang $\mathrm{ZC}$, Chen $\mathrm{L}$, et al. Inhibition airway remodeling and transforming growth factor- $\beta 1 / \mathrm{Smad}$ signaling pathway by astragalus extract in asthmatic mice. Int J Mol Med 2012;29:564-568.

32. Kao HF, Chang-Chien PW, Chang WT, et al. Propolis inhibits TGF- $\beta 1$ induced epithelial-mesenchymal transition in human alveola epithelial cells via PPAR $\gamma$ activation. Int Immunopharmacol 2013;15:565-574.

33. Nawijn MC, Hackett TL, Postma DS, et al. E-cadherin: gatekeeper of airway mucosa and allergic sensitization. Trends Immunol 2011; 32:248-255.

34. Ohbayashi H, Shimokata K. Matrix metalloproteinase-9 and airway remodeling in asthma. Curr Drug Targets Inflamm Allergy 2005:4 177-181

35. Gueders MM, Foidart JM, Noel A, et al. Matrix metalloproteinases (MMPs) and tissue inhibitors of MMPs in the respiratory tract: potentia implications in asthma and other lung diseases. Eur J Pharmacol 2006;533:133-144.

36. Sounni NE, Devy L, Hajitou A, et al. MT1-MMP expression promotes tumor growth and angiogenesis through an up-regulation of vascular endothelial growth factor expression. FASEB J 2002;16:555-564.

37. Lin YS, Tsai PH, Kandaswami CC, et al. Effects of dietary flavonoids, luteolin, and quercetin on the reversal of epithelial-mesenchyma transition in A431 epidermal cancer cells. Cancer Sci 2011;102:1829-1839.

38. Boire A, Covic L, Agarwal A, et al. PAR1 is a matrix metalloprotease-1 receptor that promotes invasion and tumorigenesis of breast Cancer Cells. Cell 2005;120:303-313.

39. Wygrecka M, Didiasova M, Berscheid S, et al. Protease-activated receptors (PAR)-1 and -3 drive epithelial-mesenchymal transition of alveolar epithelial cells-potential role in lung fibrosis. Thromb Haemost 2013;110:295-307. 